\title{
chaperer Religion, Spirituality and Mental Health
}

\author{
Esther Ansah-Asamoah, Jamie Hacker Hughes, Ahmed \\ Hankir and Christopher C. H. Cook
}

\section{Introduction}

Religion, spirituality and psychiatry share many ideals, including the importance of a holistic understanding of mental well-being, ${ }^{1}$ yet in the past have clashed. This chapter explores the journey from mutual suspicion to the recognition of their positive intersection with a focus on Britain during the period 1960-2010.

\section{Historical Context}

The divisions between religion, spirituality and medicine date back to the Enlightenment period during the seventeenth and eighteenth centuries. ${ }^{2}$ During this time, scientific communities began to develop empirical methods of explanation for behaviours and mind. While other medical fields diverged quickly, mental health continued to be closely linked with religion and spirituality until psychiatry was established as a medical discipline in the mid-nineteenth century.

From the late nineteenth century onwards, Freudian psychoanalysis understood religious belief as a form of psychopathology, attributable to the conflict between instinctual drive and intrapsychic representations of social and moral expectations: the ego and superego. ${ }^{3}$ Freud asserted that religious belief in a monotheistic God was the result of a transference phenomenon which stemmed from childhood and that belief in God was similar to an exaggerated admiration of a father by his son in early childhood. In his book Totem and Taboo, he went on to say that the roots of religion arose from the need to resolve guilt through reconciliation; this need for redemption was projected onto a heavenly father. ${ }^{4}$

The evolution of behaviourism in the early twentieth century helped to create a gap between religion and psychology, too. Behaviourists postulated that all behaviour could be traced to physiological sources such as limbs, muscles and glands. ${ }^{5}$ This allowed for the development of empirical studies, seeking to put psychology on par with other natural sciences, and simultaneously dismissed the importance of internal motivations. ${ }^{6}$ Where there were once commonalities in practice, there now existed an ever-widening chasm fuelled by discord and distrust.

By the mid-twentieth century, the influence of biological psychiatry was increasing. ${ }^{7}$ The medicalisation of mental health gradually undermined the importance of the clergy, who hitherto had been primarily responsible for the care of emotional and spiritual problems in the church community. ${ }^{8}$ Additionally, many churchgoers perceived the rise of psychiatry/ psychology as a direct 'anti-Christian' threat to biblical explanations of the human experience. ${ }^{9}$ This disconnect may have contributed to the idea that patients' religious beliefs and spiritual concerns had no place within the realm of psychiatry and were often seen as 
detrimental to their psychological health. Standard psychiatric textbooks of the 1960s, such as Mayer-Gross, Slater and Roth's Clinical Psychiatry, perpetuated the idea that religious belief could be associated with neurotic behaviours and stated that religion was practised by 'the hesitant, the guilt-ridden, the excessively timid, those lacking clear convictions with which to face life'. ${ }^{10}$

Towards the end of the twentieth century, attitudes surrounding the involvement of religion and spirituality in psychiatry in the UK began to change, at least in part, in response to the transatlantic influence. This new outlook sparked an increase in research attempting to integrate religion and spirituality into the diagnosis and treatment of psychiatric problems. A seminal paper by Allport and Ross published in 1967, titled 'Personal Religious Orientation and Prejudice', highlighted the importance of considering not whether an individual is religious or not but of how important the role of that religion is in their life. ${ }^{11}$ According to the authors, whereas 'intrinsic' religiosity provides a major motivation in life, 'extrinsic' religiosity is driven by other concerns, such as social esteem. Intrinsic religiosity, in contrast to extrinsic religiosity, has subsequently been shown in many studies to be good for mental health.

Both versions of the third edition of the Diagnostic and Statistical Manual of Mental Disorders (DSM-III and DSM-III-R) published in the 1980s were criticised for their inclusion of negative religious references and the implication that participation in religious activity was deviant from normal mental health. ${ }^{12}$ The introduction of a new $\mathrm{V}$ code (V62.89) in DSM-IV in 1994 titled 'Religious or Spiritual Problems' went a long way to reversing this negative portrayal. The category addressed scenarios where people may seek clinical advice following mental health distress due to religious or spiritual problems, such as 'loss or questioning of faith', without the need to see this as pathological. ${ }^{13}$ For the first time, it was widely recognised that individuals could have spiritual problems that were independent of mental disorders.

In 2001, Harold Koenig and his colleagues published the first edition of an encyclopaedic review of the scientific literature on religion and health (followed in 2012 by a second edition). ${ }^{14}$ Increasingly, the scientific literature, largely emanating from the United States and Europe, was providing an evidence base to support the contention that spirituality and religion were important variables to be considered in the promotion of mental well-being and in understanding the causation and treatment of mental disorders.

\section{Religion and Spirituality in Britain, 1960-2010}

In Britain, the church was responding to the rising social and cultural liberalism of the 1960s. Liberal Christianity was growing in popularity while conservative Christianity was becoming sometimes associated with intolerance, despite (or perhaps reflecting) Allport and Ross's conclusions that intrinsic religiosity was associated with less prejudice. ${ }^{15}$

In his book The Religious Crisis of the 1960s, Hugh McLeod argued that secularisation in Britain created a rift within the church in the early 1960s whereby conservative Christianity was marginalised by a more liberal tradition. ${ }^{16} \mathrm{He}$ posited that the loss of the social significance of religious beliefs, practices and institutions paved the way for reform within the church to better reflect the changing socio-political climate. He designated 1967 as the 'turning point' by which the Christian church succumbed to the tidal wave of secularism. ${ }^{17}$ Church attendance declined and a growing number of individuals began to designate themselves as being spiritual but not religious (SBNR) or having no religion at all. ${ }^{18}$ 
However, the secularisation hypothesis has been widely questioned. The sociologist Grace Davie, for example, has argued that secularisation does not necessarily correspond with a decline in religion in Britain but rather an evolution through which more people are choosing to keep their religious beliefs private, in effect 'believing without belonging' to an institution. ${ }^{19}$ This hypothesis also has been questioned and there is evidence to suggest that many people are 'neither believing nor belonging' ${ }^{20}$

In this context, at least in some quarters, discourse on religion has given way to an emphasis on spirituality. Although there is currently no universal definition of spirituality, in Britain 'spirituality' has often been understood as a more inclusive term, applicable to individuals of all faiths and none, focusing more on individual practices and beliefs rather that institutional affiliations. ${ }^{21}$ In their book The Spiritual Revolution: Why Religion Is Giving Way to Spirituality, Heelas and Woodhead acknowledge that, while practice of traditional Christianity is declining and (they say) will continue to do so for decades to come, spirituality as a stand-alone concept has not yet overtaken traditional religion. ${ }^{22}$ They propose instead that the decline in Christian religiosity can be attributed to an increase in 'holistic activity' in middle-aged women and a shift in British culture to favour subjective governance of life, where external obligations and objective societal roles defined by religious authorities are less important than individual experience. $^{23}$

The decrease in religious affiliation to Christianity has also been associated with a decline in the transmittance of religiosity through generations. ${ }^{24}$ Children and young people with religious parents are reportedly only 45 per cent likely to adopt their parents' religious affiliations. In contrast, children brought up by non-religious parents have a 95 per cent chance of being and staying non-religious themselves. ${ }^{25}$

Modernisation, industrialisation and globalisation have led to the increase of religious pluralism in Britain since 1960. Immigration has introduced new groups to the religious landscape. The growing number of religious communities has meant that the dominance of Christianity has begun to decrease. Religious pluralism is a controversial subject and was highly contested in the late twentieth century. Some scholars such as Steve Bruce have argued that pluralism weakened overall religious faith as it allowed for the element of choice, eventually leading to lower levels of religious participation. ${ }^{26}$ Linda Woodhead has suggested that increasing pluralism must eventually result in a breakdown of boundaries between religious and secular groups, resulting in de-differentiation. ${ }^{27}$ Others believe that pluralism is the result of the natural order of religious society where no religions are repressed, which is thought to generate higher levels of religious participation than religious monopolies. ${ }^{28}$ Empirically, the beginning of the twenty-first century in Britain has seen a continued rise in pluralism accompanied by a sustained decline in Christian religious practice.

\section{Changing Attitudes to Spirituality and Religion within Psychiatry, 1960-2010}

From the 1960s through to the early 1990s, attitudes to spirituality within psychiatry began to shift. Many psychiatrists and psychologists, such as Albert Ellis, were openly dismissive of religion and spirituality through to the 1980s, maintaining that religious beliefs conferred no benefits to an individual's mental state despite being a large part of many people's lives. ${ }^{29}$ In a paper he wrote detailing his experience as a psychiatrist in the late twentieth century, 
Andrew Sims remarked that in the 1960s 'there was no sense that there could be collaboration between psychiatrists and religious leaders in the care of patients' ${ }^{30}$

By the late 1980s, however, attitudes had begun to shift to a more tolerant view of the place of spirituality and religion in psychiatry. ${ }^{31}$ Since that decade, several groups affiliated with both religion and psychiatry have begun to form. The Christian Medical Fellowship held its first breakfast meeting at a national conference of the Royal College of Psychiatrists (RCPsych) in 1986, helping to alleviate some of the stigma surrounding psychiatric practice and Christian faith. One of the early meetings of the Philosophy in Psychiatry Special Interest Group (formed in 1988) was centred on the topic of religion and psychiatry. In 1991, the patron of the RCPsych, HRH The Prince of Wales, gave a speech highlighting the importance of acknowledging the impact of religion and spirituality on patients' wellbeing. ${ }^{32}$ By 1998, the message of HRH's speech had been echoed a number of times at prominent meetings attended by psychiatrists and religious leaders such as the Archbishop of Canterbury. ${ }^{33}$ The relation between religiosity and mental illness became a quickly expanding field of study and it became clear that religion and spirituality could no longer be ignored.

By the early twenty-first century, it was generally accepted that spirituality and religion provide meaningful frameworks for living and community support systems that help individuals to cope with the stresses of daily life and mental illness. In that respect, engaging in religious and spiritual belief could positively contribute to a person's mental health and improve their outcomes following psychiatric treatment. ${ }^{34}$ There have, however, been concerns surrounding the inclusion of spirituality in psychiatric practice as - it is alleged it may lead to an erosion of professional boundaries between the doctor and their patient. ${ }^{35}$

Interest in the intersections between spirituality, religion and psychiatry resulted in the formation of the Spirituality and Psychiatry Special Interest Group (SPSIG) of the RCPsych in $1999 .^{36}$ SPSIG is concerned with the spiritual and religious affairs of both psychiatrists and their patients and aims to promote an integrative approach to mental health care by stimulating discussion within the College on matters relating to spirituality and religion and proposing revisions to the psychiatric curriculum to better reflect the advances of psychiatric and religious research. ${ }^{37}$ In 2009, an edited volume, Spirituality and Psychiatry, conceived within the SPSIG, was published by RCPsych Press, providing the first critical attempt by a group of British psychiatrists and mental health professionals to address the implications of spirituality/religion for clinical practice. ${ }^{38}$

The General Synod of the Church of England held debates on mental health in 2003 and 2008. The president of the RCPsych and three members of the College were invited to observe the debate, which concluded with the passing of a motion to 'welcome the recognition within mental health services of the significance of spirituality for assessment and treatment, and encourage parishes to ensure that the support and care of people with mental health problems, their carers and NHS staff is a key priority for the Church's ministry'. ${ }^{39}$ There was clearly an implicit reference here to the way in which spirituality was increasingly being seen - at the RCPsych and elsewhere - as an important part of mental health care. The work of the RCPsych SPSIG was explicitly referred to in the Continuing Issues in Mental Health report discussed by the Synod in $2008 .^{40}$

In the last few decades, policies have been established within various national psychiatric associations that recognise the contributions of religion and spirituality to an individual's mental health. In the UK, the SPSIG first drafted a position statement making recommendations on practice in relation to spirituality and religion in psychiatry in October $2005{ }^{41}$ 
After a series of revisions, the recommendations were approved by the RCPsych as its position statement in 2011 (later revised in 2013). In 2015, the Executive Committee of the World Psychiatric Association also agreed a position statement on spirituality and religion in psychiatry which owed much to the RCPsych's position statement. ${ }^{42}$ The impact of these policies upon clinical practice has yet to be evidenced, but a number of other national psychiatric associations have gone on to provide their own policies and guidance in relation to spirituality/religion. ${ }^{43}$

The Mental Health Foundation carried out a comprehensive review of the literature on the impact of spirituality on mental health in $2006 .{ }^{44}$ They concluded it justified 'cautious optimism' about the relationship between spirituality and religion in the promotion and maintenance of good psychological health, with possible mechanisms being: locus of control and coping styles; the formation and supportive nature of social networks; promotion of healthy lifestyle choices; and, even, positive effects of the built environment. $^{45}$

\section{Religious Perspectives on Mental Health, 1960-2010}

Conservative religious perspectives on mental health have followed a similar trajectory to that of psychiatric perspectives on religion. Early suspicion and alienation meant that religious groups were reluctant to accept the involvement of psychiatrists in treating mental health issues within their community. The anti-psychiatry movement of the 1960 s and 1970s probably further contributed to negative Christian perspectives on psychiatry, too. ${ }^{46}$ Some Christians considered mental illness a result of spiritual failings such as lack of faith, which could only be treated with pastoral counselling (see also Chapter 20). ${ }^{47}$ This attitude weakened over the last few decades of the twentieth century but nevertheless persisted through to the early twenty-first century.

While psychiatry was coming to terms with the positive role that a religious support system could play in mental illness recovery, a study conducted in the United States by Mathew Stanford, published in 2007, found that many mentally ill individuals experienced negative interactions within their church communities when they sought counsel. Stanford found that, in a group of 293 Christian participants (mostly from the United States), 30 per cent reported feeling abandoned or dismissed by the church or told to ignore advice and medical prescriptions given by psychiatrists. ${ }^{48}$ While we are not aware of similar research in the UK at this time, we imagine that in at least some churches here findings would have been very similar.

\section{Increasing Influence of Service Users}

In 1997, the Mental Health Foundation conducted the first nationwide service user-led survey. The study found that more than half of the service users and survivors associated positively their religious and spiritual beliefs with their mental health. People reported that their beliefs offered them comfort, a sense of purpose and guidance. ${ }^{49}$ This research helped to realise the benefits of religion and spirituality to psychiatric treatments.

The Somerset Spirituality Project, also supported by the Mental Health Foundation, interviewed mental health service users in Somerset between late 2000 and early 2001 and found that they valued highly their religious experiences and considered them to be positive influences on their mental health. The Somerset Spirituality Project highlighted the importance of service users/survivors feeling supported in their spirituality within mental health 
services. Results from the project have been used in psychiatric training to inspire empathy and understanding towards those who are spiritually inclined (see also Chapter 13). ${ }^{51}$

\section{Spiritual Crisis Network}

The steadily increasing number of people who identified as SBNR in the late twentieth and early twenty-first centuries led to the establishment of support groups such as the Spiritual Crisis Network (SCN) in 2008. The SCN provide resources and counselling to individuals who have had spiritual experiences but may not be able to get the help they need or do not feel comfortable approaching a religious leader or a psychiatrist. Despite a lack of academic studies relating to spiritual crises, the $\mathrm{SCN}$ has developed a strategy to aid people in spiritual distress involving positive appraisals and construction of narrative frameworks. ${ }^{52}$

\section{Scientific and Medical Network}

The Scientific and Medical Network (SMN) is an international charity founded in 1973 which is dedicated to 'exploring and expanding the frontiers of science, medicine and spirituality'. It has a strong presence in the UK, with ten local groups. Since its conception, the SMN has encouraged scientists and medical professionals to incorporate spiritual and philosophical elements into their work, with a focus on enhancing understanding around parapsychological phenomena and how they influence the human experience and impact on mental health. ${ }^{53}$

\section{Developments in Other Professions}

At the same time as the developing acknowledgement of the importance of religion and spirituality to psychiatry, there have been similar developments within other mental health professions. In nursing, the Patient's Charter, introduced by the Department of Health in 1991, emphasised 'respect for privacy, dignity and religious and cultural beliefs' ${ }^{54}$ Greasley and colleagues, in a paper on spiritual care in mental health nursing published in 2001, defined spiritual care in mental health nursing as relating to 'the acknowledgement of a person's sense of meaning and purpose to life which may, or may not be expressed through religious beliefs or practices' ${ }^{55}$ They expressed, as does Sartori in a more recent paper, ${ }^{56}$ the view that, despite an acknowledgement that spirituality is important in the care of patients, it is still an area in which few nurses feel that they meet their patients' needs.

Other professions have had similar concerns. Occupational therapists (OTs) take a holistic approach to practice in which they consider the role of the body, mind and spirit in illness. ${ }^{57}$ Prior to the 1990 s, they did not generally address spiritual issues with patients although, when surveyed, the results showed that they did recognise the importance of spirituality in health and rehabilitation. ${ }^{58}$ In a follow-up study conducted in 2002, OTs reported an increase in spiritual discussions with their patients, indicative of an advancing acceptance of the role of religion and spirituality in health care. ${ }^{59}$ Despite this, in a 2004 paper, 'Spirituality in occupational therapy, theory in practice?', 60 Belcham expressed concern that some OTs continued to neglect this area in their practice, for example in assessments.

Coyle and Lochner, in an article in the 2011 issue of The Psychologist, ${ }^{61}$ summarised the areas where the interactions between religion and spirituality and therapeutic practice are important to clinical and other applied psychologists: the process of assessment; responses 
to religious or other spiritual material which may be problematic; and in the areas of training and supervision. In the latter area, as recently as 2016, Jafari found that attention to religion and spirituality in clinical and counselling psychology training programmes was still being neglected. ${ }^{62}$

\section{Spirituality and Psychiatry in Other Faiths}

The 2001 census conducted by the British government revealed that Britain is ethnically, culturally and religiously diverse, especially in larger cities such as Manchester, Glasgow and Birmingham. In London, for example, 8.5 per cent of inhabitants identified as Muslim, 4.1 per cent as Hindu, 2.1 per cent as Jewish and 0.8 per cent as Buddhist. ${ }^{63}$ This section focuses on those of Islamic faith, as its adherents make up the second largest religious group in Britain.

Over the last few decades, there has been some concern that British Muslims with mental illnesses may be avoiding mainstream mental health services, ${ }^{64}$ thus missing out on early intervention and this could be associated with poorer outcomes. Research suggests that this avoidance may be related to their religious beliefs, as many were reported to attribute their adverse experiences to supernatural causes such as 'Jinn possession' and/or 'being cursed by the evil eye of envy' ${ }^{65}$

Explanatory models of mental illness strongly influence coping strategies and helpseeking behaviours, too. Bhui and colleagues conducted in-depth interviews in the UK with 116 people from 6 ethnic groups to ascertain how they cope with mental distress. The results showed that religious coping was most commonly practised by Bangladeshi Muslims and Afro-Caribbean Christians. ${ }^{66}$

In an effort to combat the overt distrust of mental health services within the Muslim religious community, faith leaders (Imams) have joined chaplaincy services in NHS Trusts from the early 2000s. ${ }^{67}$ They have worked closely with other religious leaders and healers to provide ad hoc advice and pastoral support on faith related matters and mental health. The actual provision, however, of contemporary mental health services in the UK is not faith-sensitive insofar as it does not incorporate religious principles and modalities in treatment. A more holistic approach is needed that integrates spirituality/ religiosity with 'conventional' psychiatry. We believe that such a model would help to break down the barriers for Muslims (and others) who urgently need mental health support.

\section{Conclusion}

Religion, spirituality and psychiatry have had a complicated relationship over the years. Early mutual mistrust meant that, despite their congruent goals, there was a marked reluctance to associate them with each other. Over the decades, against a backdrop of rapid socio-political and cultural change, religion and psychiatry in Britain began to intertwine. Many psychiatrists began to see religion as a facilitator for good mental health practice and as a community-based support system which would help to improve patient outcomes. While battling the rise of secularism and the loss of social significance through religious pluralism, the Christian church has gradually adjusted its relationship with psychiatry. Other faith groups have similarly had to come to terms with a secular provision of mental health services which has often not been understanding of the spiritual and religious concerns of patients. 


\section{Key Summary Points}

- Religion, spirituality and psychiatry share many ideals, such as the importance of a holistic understanding of mental well-being, ${ }^{68}$ yet in the past have clashed. The transitions that occurred from 1960 to 2010 have significantly shaped the contemporary relationships between religion, spirituality and psychiatry in Britain.

- Interest in the intersections between spirituality, religion and psychiatry resulted in the formation of the Spirituality and Psychiatry Special Interest Group (SPSIG) of the RCPsych in 1999. In 2009, an edited volume, Spirituality and Psychiatry, conceived within the SPSIG, provided the first critical attempt by a group of British psychiatrists and mental health professionals to address the implications of spirituality/religion for clinical practice.

- At the same time as the developing acknowledgement of the importance of religion and spirituality to psychiatry, there were similar developments within a number of other mental health professions.

- The General Synod of the Church of England held debates on mental health in 2003 and 2008. The president of the RCPsych and three members of the College were invited to observe the 2008 debate, which concluded with the passing of a motion to 'welcome the recognition within mental health services of the significance of spirituality for assessment and treatment, and encourage parishes to ensure that the support and care of people with mental health problems, their carers and NHS staff is a key priority for the church's ministry'.

- A more holistic approach to the treatment of mental health difficulties is needed that integrates spirituality/religiosity with 'conventional' psychiatry. We believe that such a model would help to break down the barriers to mental health services for people of strong faith and spiritual orientation who urgently need them.

\section{Notes}

1. S. Sullivan, J. M. Pyne, A. M. Cheney, J. Hunt, T. F. Haynes and G. Sullivan, The pew versus the couch: Relationship between mental health and faith communities and lessons learned from a VA/clergy partnership project. Journal of Religion and Health (2014) 53: 1267-82; Á. de Jesüs Cortés, Antecedents to the conflict between psychology and religion in America. Journal of Psychology and Theology (1999) 27: 20-32.

2. Sullivan et al., The pew versus the couch.

3. J. W. Jones, Contemporary Psychoanalysis and Religion: Transference and Transcendence. New Haven, CT: Yale University Press, 1991.

4. S. Freud, Totem and Taboo. Boston, MA: Beacon Press, 1913.

5. K. Hilner, History and Systems of Psychology: A Conceptual Approach. Gardner Press, 1984.

6. Á. de Jesüs Cortés, Antecedents to the conflict between psychology and religion in America. Journal of Psychology and Theology (1999) 27: 20-32.

7. G. N. Grob, The attack of psychiatric legitimacy in the 1960s: Rhetoric and reality. Journal of the History of Behavioral Sciences (2011) 47: 398-416.

8. Sullivan et al., The pew versus the couch; R. F. Larson, The clergyman's role in the therapeutic process: Disagreement between clergymen and psychiatrists. Psychiatry (1968) 31: 250-63.

9. Sullivan et al., The pew versus the couch.

10. W. Mayer-Gross, E. Slater and M. Roth, Clinical Psychiatry (3rd ed.). London: Bailliere Tindall \& Cassell, 1969. 
11. G. W. Allport and J. M. Ross, Personal religious orientation and prejudice. Journal of Personality and Social Psychology (1967) 5: 432-43.

12. J. T. Richardson, Religiosity as deviance: Negative religious bias in and misuse of the DSM-III. Deviant Behavior (1993) 14: 1-21.

13. D. Lukoff, C. R. Cloninger, M. Galanter et al., Religious and spiritual Considerations in Psychiatric Diagnosis: Considerations for the DSM-V. In P. J. Verhagen, H. M. van Praag, J. J. López-Ibor et al., eds, Religion and Psychiatry, 423-44. Oxford: Wiley-Blackwell, 2010.

14. H. G. Koenig, M. E. McCullough and D. B. Larson, Handbook of Religion and Health (1st ed.). Oxford: Oxford University Press, 2001; H. Koenig, D. King and V. Carson, Handbook of Religion and Health (2nd ed.). Oxford: Oxford University Press, 2012.

15. Allport and Ross, Personal religious orientation and prejudice.

16. H. McLeod, The Religious Crisis of the 1960s. Oxford: Oxford University Press, 2007.

17. Ibid.

18. L. Woodhead, The rise of 'no religion' in Britain: The emergence of a new cultural majority. Journal of the British Academy (2016) 4: 245-61; V. Ertit, Secularization: The decline of the supernatural realm. Religions (2018) 9: 92.

19. G. Davie, Believing without belonging: Is this the future of religion in Britain? Sociology Compass (1990) 37: 455-69.

20. D. Voas and A. Crockett, Religion in Britain: Neither believing nor belonging. Sociology (2005) 39: 11-28.

21. Royal College of Psychiatrists, Recommendations for Psychiatrists on Spirituality and Religion. Position Statement No. PS03/13, November 2013, www.rcpsych.ac.uk/pdf/PS03_2013.pdf.

22. P. Heelas, L. Woodhead, B. Seel, B. Szerszynski and K. Tusting, The Spiritual Revolution: Why Religion Is Giving Way to Spirituality. Oxford: Wiley-Blackwell, 2005.

23. Ibid.

24. Woodhead, Rise of 'no religion' in Britain; Voas and Crockett, Religion in Britain.

25. Woodhead, Rise of 'no religion' in Britain.

26. R. Stark, R. Finke and L. R. Iannaccone, Pluralism and Piety: England and Wales, 1851. Journal for the Scientific Study of Religion (1995) 34: 431.

27. L. Woodhead, Intensified religious pluralism and de-differentiation: The British example. Society (2016) 53: 41-6.

28. Stark, Finke and Iannaccone, Pluralism and Piety.

29. W. R. Breakey, Psychiatry, spirituality and religion. International Review of Psychiatry (2001) 13: 61-6.

30. A. Sims, Mysterious ways: Spirituality and British psychiatry in the 20th century. Online article, 2003, www .rcpsych.ac.uk/docs/default-source/members/sigs/spirituality-spsig/andrew-sims-1-11-03-mysteriousways-spirituality-and-british-psychiatry-in-the-20th-century.pdf?sfvrsn=40adb83a_4.

31. Ibid.

32. L. Culliford, Spiritual care and psychiatric treatment. Advances in Psychiatric Treatment (2002) 8: $249-61$.

33. Sims, Mysterious ways.

34. Koenig, King and Carson, Handbook of Religion and Health.

35. C. C. H. Cook, Controversies on the place of spirituality and religion in psychiatric practice. In C. C. H Cook, ed., Spirituality, Theology and Mental Health, 1-19. London: SCM Press, 2013.

36. Sullivan et al., The pew versus the couch; A. Powell and C. C. H. Cook, Spirituality and Psychiatry Special Interest Group of the Royal College of Psychiatrists. In Reaching the Spirit: Social Perspectives Network Study Day Paper Nine, 34-9. 2006. 
37. Powell and Cook, Spirituality and Psychiatry Special Interest Group; C. Cook, A. Sims and A. Powell, Spirituality and Psychiatry. London: RCPsych Publications, 2009.

38. Cook, Sims and Powell, Spirituality and Psychiatry.

39. Mission and Public Affairs Council, Continuing Issues in Mental Health. Report No. GS1678. London: Church House, 2008, www.churchofengland.org/sites/default/files/2018-11/GS\%201678.pdf

40. Ibid., p. 15.

41. C. C. H. Cook, Spirituality and religion in psychiatry: The impact of policy. Mental Health Religion and Culture (2017) 20: 589-94.

42. Ibid.

43. Ibid.

44. Mental Health Foundation, The Impact of Spirituality on Mental Health. London: Mental Health Foundation, 2006. www.mentalhealth.org.uk/sites/default/files/impact-spirituality.pdf.

45. Ibid., p. 32 .

46. Breakey, Psychiatry, spirituality and religion; N. R. D. Crossley, Laing and the British anti-psychiatry movement: A socio-historical analysis. Social Science and Medicine (1998) 47: 877-89.

47. M. S. Stanford, Demon or disorder: A survey of attitudes toward mental illness in the Christian church. Mental Health Religion and Culture (2007) 10: 445-9.

48. Ibid.

49. Mental Health Foundation, Impact of Spirituality on Mental Health.

50. Mental Health Foundation, Taken Seriously: The Somerset Spirituality Project. London: Mental Health Foundation, 2002, www.mentalhealth.org.uk/sites/default/files/taken-seriously.pdf.

51. Ibid.

52. See the 'Research' section on the Spiritual Crisis Network's website: https://spiritualcrisisnetwork.uk /research.

53. See the 'About' section on the Scientific and Medical Network's website: https://explore.scimednet.org/index .php/about/.

54. S. Gilliat-Ray, Nursing, professionalism, and spirituality. Journal of Contemporary Religion (2003) 18: 335-49.

55. P. Greasley, L. F. Chiu and R. M. Gartland, The concept of spiritual care in mental health nursing. Journal of Advanced Nursing (2001) 33: 629-37.

56. P. Sartori, Spirituality 1: Should spiritual and religious beliefs be part of patient care? Nursing Times (2010) 106: 14-17.

57. J. S. Collins, S. Paul and J. West-Frasier, The utilization of spirituality in occupational therapy: Beliefs, practices, and perceived barriers. Occupational Therapy in Health Care (2002) 14: 73-92.

58. Ibid.

59. Ibid.

60. C. Belcham, Spirituality in occupational therapy: Theory in practice? British Journal of Occupational Therapy (2004) 67: 39-46.

61. A. Coyle and J. Lochner, Religion, spirituality and therapeutic practice. Psychologist (2011) 24: 264-6.

62. S. Jafari, Religion and spirituality within counselling/clinical psychology training programmes: A systematic review. British Journal of Guidance and Counselling (2016) 44: 257-67.

63. Office for National Statistics, Religion (2001 Census), https://data.gov.uk/dataset/17080d4d-793d-4931-925 4-a9f6c7652c3e/religion-2001-census. 
64. S. Dein and S. Sembhi, The use of traditional healing in South Asian psychiatric patients in the U.K.: Interactions between professional and folk psychiatries. Transcultural Psychiatry (2001) 38: 243-57.

65. S. M. Razali, U. A. Khan and C. I. Hasanah, Belief in supernatural causes of mental illness among Malay patients: Impact on treatment. Acta Psychiatrica Scandinavica (1996) 94: 229-33.

66. K. Bhui, M. King, S. Dein and W. O'Connor, Ethnicity and religious coping with mental distress. Journal of Mental Health (2008) 17: 141-51.

67. M. Imran Hussain, Evaluation of the Muslim Chaplaincy Service Calderdale and Huddersfield NHS Trust. Huddersfield: Calderdale and Huddersfield NHS Trust, 2014, www.cht.nhs.uk/fileadmin/site_setup/conten tUploads/Services/Non-clinical/Chaplaincy/R.C._Muslim_Evaluation_2014.pdf. 